\title{
DES-CRI(A)ÇÕES E(M) QUASE-EDUCAÇÕES
}

Elenise C. P. Andrade'; Daniela Franco Carvalho ${ }^{2}$

Descrever, escrever. Criações e $(m)$ educações. Agir nas com-fusões... "Eu estou aqui para confundir, eu não estou aqui para explicar" já bradava o Velho Guerreiro. Convidar os parênteses, as reticências, os dois pontos, as chacretes, os troféus bacalhaus a funcionarem por ressonância entre-meio, fenda, dobras e $(m)$ desdobras. Ressonâncias a provocar uma des-narrativa num futuro do pretérito... "Agora eu era o herói e o meu cavalo só falava inglês", nos sussurra Chico Buarque.

Invadir os tempos do esperado subvertendo os espaços: do/no meio da terra, da rua, do mar, da universidade, da sala de aula, dos conhecimentos, dos museus, das artes, das biologias. (Des)ocupar as experiências e não simplesmente inverter. Desentender o esperar ao propormos não haver o que esperar já que o tempo em re-existência não para e não passa. Enfretamentos. Contravenções. Esgarçar os limites da nomeação e deslizar pela correnteza do fluxo dos tremores e dos ritmos. Escravos de jó jogavam cachangá; tira, põe, deixa ficar; guerreiros com guerreiros fazem zigzig-zá; (e chacretes com chacretes dançam roda-roda-lá).

"Tereziiiiiiiiiiiiiiiiiiinha" "Como vai, vai bem? Veio a pé ou veio de trem?" "Quem não se comunica se trumbica"

Frases-sensações que ressoam pelos ouvidos e corpos de quem, durante décadas, conviveu com o multiartista Abelardo Barbosa, o Chacrinha. Múltiplo porque conseguia ${ }^{3}$ invadir, desestruturar as regras do bom senso, das opiniões e dos moralismos. Um comunicador de rádio e TV que esburacava as pressupostas linhas limpas e claras da comunicação, como a invenção e afirmação de seu nome artístico:

\footnotetext{
${ }^{1}$ Doutora em Educação - Universidade Estadual de Campinas (UNICAMP) - Campinas, SP - Brasil. Professora Titular - Universidade Estadual de Feira de Santana (UEFS) - Feira de Santana - BA - Brasil E-mail: nisebara@gmail.com

${ }^{2}$ Doutora em Educação - Universidade Estadual de Campinas (UNICAMP) - Campinas, SP - Brasil. Professora Adjunta - Universidade Federal de Uberlândia (UFU) - Uberlândia, MG - Brasil. E-mail: danielafrancocarvalho@gmail.com

${ }^{3}$ E ainda consegue, pois aqui está a invadir a apresentação de um dossiê, em 2019, para uma revista acadêmica.
}

(C) ETD- Educação Temática Digital Campinas, SP $\quad$ v.21 n.4 $\quad$ p.840-846 $\quad$ out./dez. 2019 
[...] O programa já trazia no nome, Cassino da Chacrinha, a irreverência de uma brincadeira com a própria precariedade da emissora, que funcionava numa chácara. O ouvinte acompanhava aquele caos sonoro e imaginava um cassino cheio de pessoas e muito divertido. A expressão Chacrinha pegou, ficou tão forte que Abelardo resolveu adotá-la como seu nome artístico e até hoje onde há alegria e algazarra, costuma-se dizer que ali há uma Chacrinha (SANTOS, p. 46, 2014). ${ }^{4}$

Irreverência que invade a proposta deste dossiê $e(m)$ quase-educação em atravessamentos por sociologias, educações ambientais, funk, esculturas, células, fotografias, ruas, escritas, instalações. Mrs Dalloway, Spencer Tunick, Tunga, Nego do Borel. Deleuze, Barthes, Estudos Subalternos. Personagens e conceitos trazidos por nossos convidados para divertir, inventar, versar em despertencimentos. Divagação de mundos, multiplicidades de conhecimentos, pluralidades de expressões aglomeradas a fabularem ambientes cotidianos que aqui são considerados ressonâncias num plano de sensações a proliferar pensamentos. Pretendemos, na proposta deste dossiê, servirmo-nos de termos arrancados do seu domínio, como Gilles Deleuze nos apresenta quando, juntamente com Felix Guattari, exploram o conceito de rostidade ao tencionar a expressão muro branco por ele criada e a de buraco negro, de autoria de Guattari:

\begin{abstract}
Pois buracos negros sobre um muro branco formam, precisamente, um rosto, rosto largo com bochechas brancas e perfurado por olhos negros, isso ainda não se parece com um rosto, é antes o agenciamento ou a máquina abstrata que vai produzir rosto. No mesmo lance, o problema salta, política: quais são as sociedades, as civilizações que têm necessidade de fazer funcionar essa máquina, ou seja, de produzir, de "sobrecodificar" todo o corpo e a cabeça com um rosto, e com que objetivo? Não é óbvio, o rosto da amada, o rosto do chefe, a rostificação do corpo físico e social... Eis uma multiplicidade, com pelo menos três dimensões, astronômica, estética, política. Em nenhum dos casos fazemos uso metafórico, não dizemos: são "como" buracos negros em astronomia, é "como" uma tela branca em pintura. Nós nos servimos de termos desterritorializados, ou seja, arrancados de seu domínio, para reterritorializá-los em outra noção, o "rosto", a "rostidade" como função social (DELEUZE, p. 15, 1998). ${ }^{5}$.
\end{abstract}

Rostificação na explicação - tão cara às educações, sejam em metodologias, formações, memórias, pesquisas, escritas - reivindicação primal, brutal de arregimentação de modelos a pensar. Explicação descritiva, argumentativa, justificativa... Tempo cronológico arregimentado ao movimento da recognição. Ritmo cronometrado... tic-tac-tic-tac. Fronteira estabelecida entre o movimento e o estático, o antes e o depois, o som e a pausa. "Um minuto de comercial, alô, alô Terezinha..."

\footnotetext{
${ }^{4}$ SANTOS, Elias P. Sorria meu bem, sorria: no ar, o Cassino do Chacrinha! Pós-Graduação em Comunicação Social, Universidade Federal de Minas Gerais (Dissertação de Mestrado), 2014.

${ }^{5}$ DELEUZE, Gilles; PARNET, Claire. Diálogos. São Paulo: Editora Escuta, 1998.
}

(C) ETD-Educação Temática Digital Campinas, SP $\quad$ v.21 n.4 $\quad$ p.840-846 $\quad$ out./dez. 2019 
Neste um minuto, com-vidamos Tom Zé para cantar "Eu tô te explicando/Prá te confundir/Eu tô te confundindo/Prá te esclarecer/Tô iluminado/Prá poder cegar/Tô ficando cego/Prá poder guiar ${ }^{\prime \prime}$. Agora o convite se estende a uma conversa com Jô Soares:

Tom Zé: Onde é que tá anotado aí o negócio do Atoladinha ${ }^{8}$ ?

Jô Soares: O negócio do que?

Tom Zé: (cantando) Tô ficando atoladinha, tô ficando...

Jô Soares: Acho que não tem isso aqui não

Tom Zé: O negócio do Atoladinha é o seguinte: O Globo, do Rio, fez um certo escândalo porque eu disse que o refrão da Atoladinha era uma das ondas concêntricas que a bossa-nova tinha feito desencadear. Parece uma coisa tão diferente e tão distante, mas isso não é verdade. Então eu fiz uma espécie de exegese para explicar o que eu tinha dito antes: o refrão da Atoladinha é um metarrefrão microtonal $e$ polissemiótico.

Jô Soares: Agora ficou claro!

Podemos imaginar que Tom Zé tenha sido convidado por Chacrinha a participar de uma apresentação do $\mathrm{MC}$ Bola de Fogo. Atualização junto à genialidade deste artista ao desestruturar os padrões de moralidade e normalidade ${ }^{9}$ tão presentes nos espaços brasileiros, sejam midiáticos ou não, que poderia estar respondendo ao famoso questionamento do apresentador: "Vai para o trono ou não vai?" ou então a plateia ser questionada com "Vocês querem bacalhau?". Trono sem monarquia nem poder, um querer que nada significava para as pessoas, já que o bacalhau estava cru e salgado. Intervalos-poros no rosto identificador e, por consequência, detentor de indícios classificatórios, portanto, hierarquizantes.

\footnotetext{
${ }^{6}$ Versos da música “Tô”, de Tom Zé. https://www.letras.mus.br/tom-ze/164918/ (Álbum “Estudando o samba”). ${ }^{7}$ O objetivo da ida do música ao Programa do Jô foi a divulgação de seu álbum Danç-Eh-Sá, lançado em 2006. Esse trecho está disponível em: https://youtu.be/hubD31XaHqU. Publicado em 16/02/2009.

${ }^{8}$ MC Bola de Fogo e seu hit Atoladinha, de 2005. Cd "Bola de Fogo e as foguentas".

${ }^{9}$ Um comentário complementar sobre a fala de Tom Zé, realizada no blog de Túlio Ceci Villaça: "Sua participação no talkshow do Jô Soares reverberou no meio musical pela análise da melodia ascendente por quartos de tom, mas levantou mesmo a plateia pelo elogio da afirmação feminina pela sexualidade, ao identificar neste refrão uma reação feminina à castração judaico-cristã que proíbe a mulher de gozar". Funk, Freud, feitiço, as Foguentas e as fogueiras da Santa Inquisição. Disponível em https://tuliovillaca.wordpress.com/2010/06/14/funk-freudfeitico-as-foguentas-e-as-fogueiras-da-santa-inquisicao/
}

(C) ETD- Educação Temática Digital Campinas, SP v.21 n.4 p.840-846 $\quad$ out./dez. 2019 
E, pior ainda, as pessoas são continuamente jogadas nos buracos negros, dependuradas em muros brancos. É isso ser identificado, fichado, reconhecido: um computador central funcionando como buraco negro e passando sobre um muro branco sem contornos. (DELEUZE; PARNET, 1998, p. 15) ${ }^{10}$.

"É isso ser identificado, fichado, reconhecido" por uma educação que é continuamente jogada nesses buracos negros, de onde ninguém escapa, dependurada em muros brancos. Como desterritorializar essa 'sobrecodificação' em sua rostidade? Quasemetodologias, quase-escrita. Quase-educação? Descriação para o âmbito do rosto da buzina e da barriga do Chacrinha, da dança das chacretes e suas bundas e pernas? Rosto que desaba quando a plateia canta com o Velho Guerreiro e os cantores/as dublam abertamente. Ruído de linguagem. A dublagem é incorporada no funcionamento do programa. O original, com o cantor cantando, não tem mais muita importância nesse alisamento. A plateia canta. $O$ cantor dubla a ele mesmo. Cantor-plateia. Plateia-cantor.

Trabalhando o rádio mais como um meio de expressão do que um meio de transmissão, conforme defende Rudolf Arnheim (1979), o Cassino da Chacrinha se utilizava de efeitos sonoros que ajudavam na sua identificação, mas que também traziam um verdadeiro caos sonoro. Caos que era uma das marcas registradas de seu criador: ruídos, som ambiente, aplausos, movimentos de mesas, barulhos de chocalhos, copos, garrafas, pratos, talheres, panelas etc. Tudo isso misturado aos shows de música e alegria, nos quais o apresentador conversava e entrevistava seus convidados (muitas vezes fictícios), ativando a imaginação dos ouvintes que ligavam para a emissora querendo reservar um lugar no tal cassino... (SANTOS, p. 46, $2014)^{11}$

Quase-educação em uma aposta num quase que tenta esvaziar. Um esvaziar que não é negar. Espaço-tempo numa resistência à nomeação que uma escrita "em nome de" exige. Des-cri(a)ções na observação do mundo, no sentido de inventar outras descrições: desescrever. Ex-crever uma escrita em fuga e em combate à fixidez. Forma-conteúdo-função movimentando-se em estéticas de ações sob outros ângulos.

\footnotetext{
Vê-se um rosto, captam-se as suas especificidades e nele vê-se também outro, inesperado, e não é porque se vê de mais perto ou melhor, em detalhe (quer dizer, vê-se qualquer coisa que estava escondida porque minúscula, escondia-se e uma vez descoberta exibe-se e deixa-se identificar, fez sempre parte do visível, esteve sempre num certo espaço). Não é aqui o caso. Não é uma questão de aspecto, é porque se "vê" uma outra natureza, um impensado, uma singularidade, incompreensível, incaptável, um intruso que surge aí onde não o esperamos, inquietante, que "salta aos olhos", mas continua indiscernível (GODINHO, p. 70, 2010) $)^{12}$.
}

\footnotetext{
${ }^{10}$ DELEUZE, Gilles; PARNET, Claire. Diálogos. São Paulo: Editora Escuta, 1998.

${ }^{11}$ SANTOS, Elias P. Sorria meu bem, sorria: no ar, o Cassino do Chacrinha! Pós-Graduação em Comunicação Social, Universidade Federal de Minas Gerais (Dissertação de Mestrado, 2014.

${ }^{12}$ GODINHO, Ana. Como desfazer para si próprio o seu rosto? In Cadernos de Subjetividade, n. 12, 2010.

Disponível em:
}

(C) ETD- Educação Temática Digital Campinas, SP $\quad$ v.21 n.4 $\quad$ p.840-846 $\quad$ out./dez. 2019 
Desentender as ordens de comando na desfaçatez dos espaços-tempos autoritários de cotidianidade e explicações e conceituações, assim como podemos pensar o verbete Aimonimia do Dicionário das Tristezas Obscuras ${ }^{13}$ : "O medo de que aprender o nome de algo - um pássaro, uma constelação, uma pessoa bonita - vai estragar tudo. Transformando uma descoberta do acaso, em uma casca conceitual vazia".

Com e pela potência de intercessores das mais diversas artes, propomos um dossiê movimento de resistência, no qual a complexidade do rosto poroso invada as escritas, a educação, as metodologias, as políticas curriculares, as cidades, as formações de professores. Um congregar de textos que não subvertem, mas vertem até o buraco negro não conseguir mais sugar, para que o muro branco possa ser perfurado de sombras e cores. Um dossiê cujo intuito não é salvar através do conhecimento, nem emancipar, mas assumir rostos para deles produzir linhas de fuga nesse fascismo cotidiano. Tornarmo-nos ex-pressos (com) o mundo.

E com a buzina!

E com o bacalhau!

E com as chacretes Helen Baiana e Dheny Finco que, ao fazerem o gesto característico do "roda, roda, roda e avisa" para a câmera, são abordadas com o Velho Guerreiro empunhando um microfone, onde podemos escutar... "Abelardo Barbosa, está com tudo e não 'tá prosa. Menino levado da breca..."

E lá vem o Chacrinha para mais um programa. Casaca vermelha de lantejoulas, flor amarela na lapela, gravata-borboleta verde brilhante, microfone e buzina presos ao corpo, um chapéu com plumas alaranjadas, óculos e a tradicional marca de batom vermelho na bochecha do lado esquerdo.

Alôooooooié.... ahhhh... ahhhh... alôooooo

Oi! Vamos chamar inicialmente, para um abraço no velho guerreiro, vamos receber Ana Godinho. Palmas para ela! Algumas palavras para nossa plateia:

"No cruzamento entre a filosofia e as artes em geral surge um espaço de experimentação singular e dele surge uma multiplicidade de problemáticas a partir das quais formularemos duas questões: o que move um corpo? Como se forma uma forma?". Nisto, uma das chacretes cometa: "No ensaio $O$ vazio e o movimento, a pesquisadora portuguesa desenvolverá essas qustões a partir de "condições e procedimentos envolvidos na produção dos corpos e do vazio tomando o vazio e depois o ritmo como condição do movimento".

https://cadernosdesubjetividade.files.wordpress.com/2013/09/cadernos2010 baixaresolucao.pdf

${ }^{13}$ Disponível em: https://noosfera.com.br/o-dicionario-das-tristezas-obscuras/

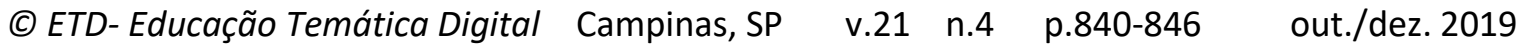


A plateia vai ao delírio e Chacrinha a cumprimenta com beijos e apertos de mão ao som de aplausos da plateia.

A plateia segura balões coloridos e as chacretes dançam com seus colants prateados em plataformas suspensas. Continua a música. Vamos receber as nossas amigas da Universidade Federal de Santa Catarina Michele Fernandes Gonçalves e Marina Lopes e Gomes para apresentar o "Por entre céu e dunas, montanhas e mar - fragmentos de pesquisa e escrita em educação"! Ai... ai... Tudo que eu falar vocês falam ai...

"O que pode o encontro entre fragmentos de pesquisa? O que pode uma escritafragmento, feita a muitas mãos, no dizer com esse encontro? Direcionadas por essas indagações e pela vontade de criar, naquilo que comumente denominamos Educação, planos assimétricos nos quais a pesquisa e a escrita possam forjar novas superfícies, novos poros que extravasem outras maneiras de fazer." dizem as convidados do sul do Brasil!

Quem gritar mais alto vai ganhar dois mil cruzeiros aí!

Êêe...

\section{Olê, olá... o Chacrinha tá botando pra quebrá!}

Reeeeeeeeeee... Oi! Vamos reeeeeeeeeceber! Vamos receber as encantadoras Laís de Paula Pereira e Shaula Maira Vicentini de Sampaio da Universidade Federal Fluminense! $A i$. Ai. Ai ai ai ai ai. Vai pro trono ou não vai?

Neste instante, alguém da plateia grita, levanta as mãos e diz: "Elas são as autoras de Fragmentos de uma quase-educação-ambiental: experimentações de um devir-caiçara, onde apresentam o que denominam de "quase-educação-ambiental", para se referirem às experimentações e aos processos de produção de realidades com fotografias e narrativas - a partir e com e através de histórias narradas pelos caiçaras - que remetem a lembranças e esquecimentos foto-não-grafados, não 'representando' histórias, realidades dadas e paradas, mas 'apresentando possibilidades' de realidades outras, diferentes, estranhas e desconhecidas." Vai de bacalhau, minha filha. Você é um bocado assanhada, hein?

Alô! E atenção! Daqui a pouco vocês vão ver a novela mais comentada do Brasil!

E agora, o homem que mais entende disso no Brasil!

Tiago Duque, da Universidade Federal do Mato Grosso sai do túnel e recebe das mãos da chacrete o microfone: "Quem ainda ri da bicha preta, efeminada e pobre? Funk, (re)conhecimento e direitos LGBT em tempos de pânico moral" é o que trago para esse dossiê, para discutir a ideia de reconhecimento através da imagem da bicha preta, efeminada e pobre, para pensar a questão dos direitos LGBT no contexto contemporâneo. Isso é feito a 
partir das reações críticas de LGBT e não LGBT diante do clipe da música Me Solta, do cantor de funk Nego do Borel."

Aêê!!! Palmas para ele!

Roda, roda, roda... roda e avisa.

Alô... quem vai querer mandioca aí?

Uma tomada de cena com Chacrinha em frente à câmera. Um recado dos patrocinadores.

Ei! Atenção! Esse programa é ao vivo! Em rede nacional! Todos os sábados a partir das quatro da tarde. Com entrada franca! Podem entrar! Podem entrar! E entra, já de braços levantados acenando para a plateia, Amanda Leite, da Universidade Federal de Tocantins, com o cartaz contendo sua proposta: "Com Spencer Tunick: Fotografia, arte contemporânea e educação sugiro reflexões sobre Fotografia, Arte Contemporânea e Educação nas interfaces com obras de Roland Barhtes (A Câmara Clara, 1984) e Jacques Rancière (O espectador emancipado, 2012)".

Dirigindo-se à plateia Chacrinha informa: Essa turma aqui não comeu hoje. Depois do programa vou dar sanduiche a vocês. Mortadela. Salsicha.

Vocês querem mais?

Mais um! Mais um! Mais um!

Quem gritar mais alto vai definir!

Luzes piscando, muita serpentina no chão, jurados e plateia dançando, quando as chacretes Helen Baiana e Dheny Finco pegam o microfone, rebolam e cantam: "Vermelhos ritmos $\mathrm{e}(\mathrm{m})$ biologias: sonoridades de ruptura com o esperado na singularidade de viver mulher". Mais uma rebolada, apontam o dedo para a câmera e acrescentam: "Retirar da vida, do corpo, da resistência, a necessidade de um tempo 'vivido', de precisões conceituais biológicas e vazar pelas bordas de um vermelho arrastado por signos da arte. Mulheres (s)em educação a des-afiar as estrias no tempo, e, com elas, abandonar as certezas e explicações rumo a uma experiência estética."

Alô atenção! Isso aqui é um programa de cultura, é um programa de respeito. Eu quero muito respeito aqui dentro! Senão ponho na rua! Venham confundir!

A câmera fecha no rosto do Grande Guerreiro, que agradece:

Oi! Muito obrigado!

Oi! Muito boa noite!

Ao pessoal da Revista ETD, aquele abraço!

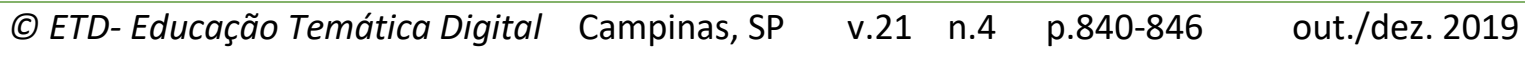

